\title{
ARTICLE \\ Opportunities and Challenges of Rehabilitating Degraded Land in the Case of Cheha Woreda, Gurage Zone, SNNP Region, Ethiopia
}

\author{
Tekilil Wolde* \\ Department of Natural Resource Management, Wolkite University, Ethiopia
}

\section{ARTICLE INFO}

Article history

Received: 1 September 2021

Accepted: 23 September 2021

Published Online: 29 September 2021

Keywords:

Land rehabilitation

Challenges

Opportunities

\begin{abstract}
The research was conducted in chaha wereda gurage zone SNNP region of Ethiopia. The aim of the study was to assess opportunity and challenges of degraded land rehabilitation. From the total population of the study area $20 \%$ (73) respondents were selected in order to achieve the objective of the study at hand, for the study both primary and secondary data was generated. The primary data collection was started with a preliminary survey followed by a key informant interview, focus group discussion, and household survey with questionnaires. The secondary data were collected from books, unpublished thesis, project report, and workshops, open ended questionnaire and checklists for interview. The households were selected using stratified sampling technique (Cochran) sample size formula the process of analysis of the study was carried out using qualitative description and quantitative analysis. The collected data were analyzed using descriptive statistics, the quantitative data were analyzed frequency and percentage when appropriate the qualitative data were discussed to substantiate the study. And the results were expressed in the form of tables and graphs. The findings of the study indicated that limited labor availability, high cost of maintenance. Lack of knowledge, soil conditions, high surfaces runoff, poor vegetation coverage, poor monitoring and evaluation, poor implementation and poor training on the technology use are major challenges.
\end{abstract}

environmental changes occurring without historic patterns. These rapid environmental changes and degradations are brought about by land cover changes, fragmentation, invasive species, and pollution. The land use change in East Africa have transformed natural land cover to farm lands, grazing lands, human settlements and urban centers at the exposition of natural vegetation. These changes are associated with deforestation, biodiversity loss and agricultural intensification ${ }^{[4]}$.

Land degradation includes all process that diminishes the capacity of land resources to perform essential functions and services in ecosystems ${ }^{[1]}$. Principal processes of land

*Corresponding Author:

Tekilil Wolde,

Department of Natural Resource Management, Wolkite University, Ethiopia;

Email:woldetekilil@gmail.com 
degradation include erosion by water and wind, chemical degradation (comprising acidification, salinization, fertility depletion, and decrease in cation retention capacity), physical degradation (comprising crusting, compaction, hard-setting, etc.) and biological degradation (reduction in total and biomass carbon, and decline in land biodiversity) ${ }^{[9]}$.

\subsection{Statement of the Problem}

In Ethiopia, the heavy dependency of people's livelihoods on agricultural and in appropriate use of natural resource resulted in the fast and vast land degradation. On the other hand, development of agricultural sector partly depends on land productivity ${ }^{[2]}$. However the resource is seriously threatened by land degradation and aggravates the food insecurity problems in the country through its adverse impact on the crop yield. The country could not feed its population at present and it will have difficulties during in the near future partly due to serious land degradation. Therefore, improving productivity of land is so crucial in improving the agrarian population in particular and the overall economy of the country in genial without the proper management of land resource. It becomes a challenge for Ethiopia to feed the incising population. As a result, there should be appropriate land management systems to improve the productivity of land particularly in lowland areas where the problem of land degradation is severe. In the study area some of land degradation problems like deforestation, improper land use, lack of management, climatic condition and declining of soil fertility. Therefore, in an attempt to contribute in bridging the above stated gap, the study was focused on assessing challenges and opportunity of land rehabilitation practice.

\subsection{Objective of the Study}

The general objective of the study is to assess the opportunity and challenge of degraded land rehabilitation practice on the study area.

\subsection{Research Question}

Based on the above specific objectives, the research attempts to answer the following question:

$\checkmark$ What are opportunities for degraded land rehabilitation in the study area?

$\checkmark$ What are challenge and shortcomings in undertaking land rehabilitation practice?

$\checkmark$ What are the main socio-economic, institutional and natural factors that affect the practice of land rehabilitation?

\subsection{Significance of the Study}

The study will generate information for different stakeholders, researchers, policymakers, governmental and nongovernmental organization, and farmer's local level organizations to design develop effective land rehabilitation practices and strategies.

\subsection{Scope of the Study}

The research is geographically delimited to cheha wereda, gurage zone, SNNP region in 2019 G.C. The conceptual delimitation of the study is only focusing on assessing the opportunities and challenges of degraded land rehabilitation practices on study area alone.

\section{Methodology}

\subsection{Description of the Area}

\subsubsection{Location}

The survey was conducted in Cheha wereda, Gurage Zone SNNP, and Ethiopia. This area is located $171 \mathrm{~km}$ Southwest from Addis Ababa and $17 \mathrm{~km}$ from Wolkite town ${ }^{[7]}$.

\subsubsection{Topography and Vegetation}

According to (Cheha woreda, Buchace kebele unpublished annual report 2020) the percent of topographic features constitute flat. $98 \%$ and up and down $2 \%$ that is suitable for farming practice and the vegetation type in the study area dominantly characterized by Eucalyptus, Mango, Bamboo, inset etc are dominantly characterized vegetation. The land has a dominantly level or flat topography that is suitable for farming.

\subsubsection{Soil Type}

The study area was endowed with different soil colors. Black: it covers $30 \%$; Brown: it covers $10 \%$ and Red: it covers $60 \%$ even though the dominant soils are red color and black color soils ${ }^{[7]}$. These types of soils are very useful for the production of different fruits and the dominant soil color is red color.

\subsubsection{Climate}

The climate condition of the study area is kola. The annual rainfall is $1200 \mathrm{~mm}$ and altitude $13000-1565$ the maximum temperature of the area is $30{ }^{\circ} \mathrm{C}$ degree centigrade and minimum temperature of $25{ }^{\circ} \mathrm{C}$ degree centigrade. The rainfall is high in summer season (June August) and a little rainfall in the winter season ${ }^{[7]}$.

\subsubsection{Land Use and Farming System}

The land use of the study area is both crop cultivation 
and livestock rearing. The most important crop in the study area cereal crops includes Inset, teff and maize. Leguminous and vegetation are mainly grown in the study area. The dominantly cultivated annual crops are cereal crops such as maize, Teff, Inset and legumes are grown in the study area. The dominant livestock productions are donkey, ox, hen and cow. Those types of framing system the major source of income through which farmers work to enhance their living standard. Generally, the socioeconomy of the society in the study area is dominated by agricultural production system. The land was covered different activities such as grazing land, land forest, water body, crop land and settlement.

\subsection{Sources and Types of Data}

\subsubsection{Sources of Data}

The source of data was by using both primary and secondary data sources. The primary data were collecting through structured and interviews, open ended questionnaires and filed observation. Because it is a vital way to obtain the relevant data for the community about the challenge and opportunity of land degradation, the secondary data were collected from different published and unpublished document, project reports and different government offices and internet service.

\subsubsection{Types of data}

The study was used both quantitative and qualitative data types.

\section{Quantitative data}

The data were collected from the wereda household and was converting into numerical form or it was obtained as numerical form from secondary sources.

\subsection{Sampling Technique and Sampling Size}

In the study purposive sampling techniques were used and the total population of study area is 10,000 . The sample size of the study was determined statistically using the formula described by ${ }^{[3]}$ as:

$$
\text { Sample size, } \mathbf{n}=\mathbf{N} * \frac{\frac{Z^{2} * p *(1-p)}{e^{2}}}{\left[N-1+\frac{Z^{2} * p *(1-p)}{e^{2}}\right]}
$$

Where

$\mathrm{N}=$ Population size

$\mathrm{Z}=$ Critical value of the normal distribution at the required confidential level

$\mathrm{P}=$ sample proportion $\mathrm{e}=$ Margin of error

$\left(10,000 *\left(1.96^{2}\right) * 0.5 *(1-0.5) /\left(0.05^{2}\right) /(10000-\right.$ $\left.\left.1+\left(\left(1.96^{2}\right) * 0.5 *(1-0.5) /\left(0.05^{2}\right)\right)\right)\right)$

$=10000 *(3.8416) *(0.25) / 0.0025 /(9999+(3.8416) * 0.5 *($

$0.5) / 0.025)))$

$=10000 * 0.9604 / 0.0025 /(9999+0.9604 / 0.0025)$

$=10000 * 384.16 / 9999+384.16$

$=10000 * 384.16 / 10383.16$

The value of sample size $n=369.9$ Household

But limitation of time, budget and other constraint we cannot collect data from all households so assessing the study area use $20 \%$ of the $369 * 0.2=73$.

\subsection{Methods of Data Analysis}

The data were analyzed and interpreted according to the nature of the data. Therefore, all required data were analyzed by using the descriptive data analysis method using the recent version of SPSS software to describe, summarize and present quantitative and qualitative data. The interpretation was presented in the form of tables, graphs, and percentages.

\section{Results and Discussion}

\subsection{Demographic Characteristics of Household}

In demographic parameter: age, sex educational status, material and family size status of respondent are discussed are base line for study since land rehabilitation practice are participatory program encompasses all parameter of the respondent is important to determine which have opportunities and challenge of land rehabilitation practice as Table 1, among the interviewed households' $72.6 \%$ were male headed household and remaining $27.4 \%$ were female headed household. This shows that the majority is males because of males have especial knowledge than females on the land. Below Table 1 shows that about $23.3 \%$ of $20-30$ age, $28.8 \%$ of $31-40$ age, $35.6 \%$ were $41-$ 65 and $12.3 \%>65$ age group. Then among them most of people are the age $>65$ were UN productive and were 4165 more productive. Age classes of $<15$ and $>65 \%$ are categorized as unproductive and 15-65 more productive age class. The productive age class is playing very important roles in any development activities including of land rehabilitation practices activities in the study area.

Marriage characteristic have an effect up on development initiatives as Table 1 about $27.4 \%$ single, $72.6 \%$ married. Household that has household head and children undertaking collective participatory actions on agricultural land. But those who have the single can undertake the action individually cannot easily complete the rehabilitation action in on farm lands. The educational 
status is one of the factors on the community land rehabilitation practices. The community having large number educated individual easily accepts technology regarding rehabilitation practices and undertaking and implement it practically ${ }^{[6]}$. The below Table 1 shows that among total numbers of respondents that attends school currently and educated including who are able to write their name is almost $52 \%$ and remaining respondent almost $48 \%$ was illiterate. This shows that most of the respondents who cannot participate in the area land rehabilitation practices were illiterate.

Religion is one of the factors which affect rehabilitation practices in the case of study area context. There are different religious holidays that do not allow the labor work regarding respective religious. Majority of the people in the study area were dominantly Orthodox and Muslims they enforced to celebrate this holiday in the month. This may have a negative effect on the rehabilitation practices. The below Table 1 shows that among total number of respondents the dominant group almost $50.7 \%$ were Orthodox and $45.2 \%$ follows Muslim and the remaining $4.1 \%$ protestant.
Table 1. Respondents sex, age, education characteristics $(\mathrm{n}=73)$

\begin{tabular}{|c|c|c|c|}
\hline Parameter & Status & Number & $\%$ \\
\hline \multirow{3}{*}{ Sex of respondent } & Male & 53 & 72.6 \\
\hline & Female & 20 & 27.4 \\
\hline & Total & 73 & 100.0 \\
\hline \multirow{5}{*}{ Age of respondent } & $20-30$ & 17 & 23.3 \\
\hline & $31-40$ & 21 & 28.8 \\
\hline & $41-65$ & 26 & 35.6 \\
\hline & $>65$ & 9 & 12.3 \\
\hline & Total & 73 & 100.0 \\
\hline \multirow{5}{*}{$\begin{array}{l}\text { Education of } \\
\text { respondent }\end{array}$} & Illiterate & 35 & 48 \\
\hline & Primary & 16 & 21.9 \\
\hline & Secondary & 7 & 9.6 \\
\hline & Diploma and above & 15 & 20.5 \\
\hline & Total & 73 & 100 \\
\hline \multirow{4}{*}{$\begin{array}{l}\text { Religious of } \\
\text { respondent }\end{array}$} & Orthodox & 37 & 50.7 \\
\hline & Muslim & 33 & 45.2 \\
\hline & Protestant & 3 & 4.1 \\
\hline & Total & 73 & 100.0 \\
\hline \multirow{3}{*}{$\begin{array}{c}\text { Material status of } \\
\text { respondent }\end{array}$} & Married & 53 & 72.6 \\
\hline & Single & 20 & 27.4 \\
\hline & Total & 73 & 100.0 \\
\hline
\end{tabular}

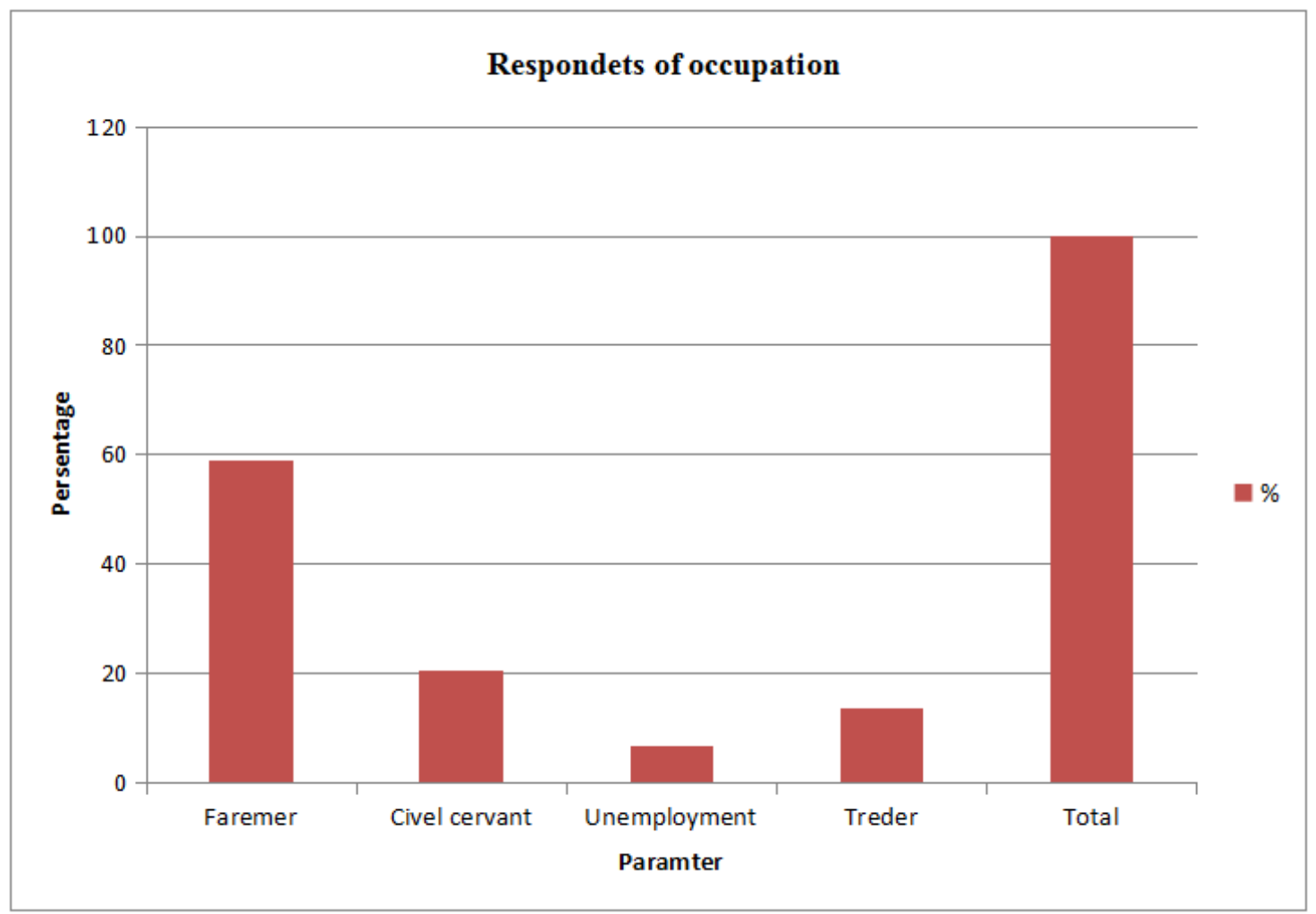

Figure 1. Occupation categories of respondents in the study area 
In the above chart the occupation of respondent the majority are almost $59 \%$ are farmer, and the remaining $41 \%$ are other additional workers such as civil servant unemployment and also traders. This shows that the majority of farmers are only depend on natural resource and less participate on land rehabilitation practices because of lack of awareness, lack of knowledge.

\subsection{Form of Land Degradation in the Study Area}

According to ${ }^{[8]}$ findings, the study area was requested to rank which of the below forms of land degradation is common in their farm land (Table 2). As it was clear that soil fertility decline $(54.8 \%)$ is the top of all forms and ranked as $1^{\text {st }}$ followed by forest degradation $(42.5 \%)$ and gully erosion $(2.7 \%)$ as $2^{\text {nd }}$ and $3^{\text {rd }}$ rank perceptively. This shows that the dominant form of land degradation was soil fertility and decline and gully erosion was less concern form community point of view in the study area.

Table 2. Form of land degradation $(n=73)$

\begin{tabular}{cccc}
\hline Parameter & Frequency & $\mathbf{\%}$ & Ranking \\
\hline Gully erosion & 2 & 2.7 & $3^{\text {rd }}$ \\
Forest degradation & 31 & 42.5 & $2^{\text {nd }}$ \\
Soil fertility & 40 & 54.8 & $1^{\text {st }}$ \\
Total & 73 & 100.0 & \\
\hline
\end{tabular}

Sources: structural interview HH,(2020)

\subsection{Common Land Rehabilitation Practices}

As Table 3 below shows that all individuals in the study area activity involved in land rehabilitation practice listed below. Accordingly starting from the most dominant land rehabilitation practice in the study area, around $24.7 \%$ of individual in the study area replied that that use of soil bund and to divert it in to appropriate water way in the dominant land rehabilitation practice in our area followed by use of SWC which constitutes around $45.2 \%$ and also beyond the forestation and reforestation which accounts $30.1 \%$ as means of land rehabilitation practice was common but least concern from community point of view.

Table 3. Land rehabilitation practice $(n=73)$

\begin{tabular}{ccc}
\hline Parameter & Frequency & Parentage $\%$ \\
\hline A forestation and reforestation & 22 & 30.1 \\
SWC & 33 & 45.2 \\
Soil bund & 18 & 24.7 \\
Total & 73 & 100.0 \\
\hline
\end{tabular}

Sources: structural interview HH,(2020)

\subsection{Soil Fertility Management Practice in the Study Area}

Farmers at individual level of practice different land management activities mainly to increase agricultural yield and to conserve the natural environment on their plot of land farmer apply chemical fertilizer to obtain high agricultural yield. Inorganic fertilizer application is the perquisite in the study area $19.2 \%$ as many part of the country experience due to loss of soil fertility which is caused by erosion according to survey results, manuring, crop rotation $20.5 \%$ and $27.4 \%$ respectively were one of the most important method of improving soil fertility as well as conserving soil on cultivated field. But only $32.9 \%$ of inter cropping the respondent in the study area. This shows that individual in the study area does not give attention to agro forestry practice.

Table 4. Soil fertility management practice $(n=73)$

\begin{tabular}{ccc}
\hline Parameter & Frequency & $\mathbf{\%}$ \\
\hline Chemical fertilizer & 14 & 19.2 \\
Manu ring & 15 & 20.5 \\
Crop rotation & 20 & 27.4 \\
Inter cropping & 24 & 32.9 \\
Total & 73 & 100.0 \\
\hline
\end{tabular}

Sources: structural interview HH, (2020)

\subsection{Opportunity of Degraded Land Rehabilitation}

\subsubsection{Family Members Motive to Involve in Land Rehabilitation Practice}

Regarding the involvement and support of household member to land rehabilitation practice in study area almost $68.5 \%$ of respondents of family members are willing to participate in any natural resource conservation activity.

Table 5. Willingeness to particpat land rehablitation practice $(n=73)$

\begin{tabular}{ccc}
\hline Items & Frequency & \% \\
\hline Yes & 50 & 68.5 \\
No & 23 & 31.5 \\
Total & 73 & 100.0 \\
\hline
\end{tabular}

Sources: structural interview HH,(2020)

\subsubsection{Assistance/Cooperation of Neighborhoods for Land Rehabilitation Practice}

Respondents were also asked to tell the assistance and cooperation of the neighboring people to land 
rehabilitation practices. Accordingly, above the table of respondents in indicated that there is cooperation among the societies to rehabilitation degraded areas on their farm plot and community land respondents show that the majority of the people in their localities are willing to perform any resource management practice. A number of reasons were in dictates by the respondents as the way the assistance gained increase over time. The sampled household heads who indicated increase in assistance over time gave the reason: people give attention for long term benefits rather than working for short term benefits. Many people are trying to focus on their social gain rather than personal benefit increase in the level of awareness among some communities to minimize problems of land degradation in cooperated manner than performing at individual level. The increase in awareness among communities regarding the problem of land degradation. As a result, there are extensive efforts made by all stakeholders to conserve natural resources and to perform land restoration practice in the study area.

\subsection{Challenge of Land Rehabilitation Practice in the Study Area}

\section{Socio-economic, institutional and environmental challenge of land rehabilitation practices in the study area}

As shown in the Table 6 there were many challenges associated with land rehabilitation practice in the study area. Regarding socio-economic challenges about 31.5\% respondent replied that lack of materials like stone to undertake land rehabilitation practice and also inorganic fertilizer in the major challenge followed by high cost maintenance $23.3 \%$ and lack of knowledge how to perform and maintain the structures $45.2 \%$ are the major socio-economic challenge from community point of view. The environmental challenges about $16.4 \%$ respondent poor vegetation like deforestation to undertake land rehabilitation practice climate condition $32.9 \%$ and remaining soil condition land rehabilitation practice. Accordingly, about $30.13 \%$ of individuals confirmed that lack of awareness of introduced the fundamental institutional factor that affects our land rehabilitation practices, poor Implementation design $26 \%$ and poor monitoring $16.4 \%$ and remaining $27.47 \%$ replied that poor training on technology use affects our land rehabilitation practices. As the result shows that lack of awareness is the major institutional challenge in the study area.
Table 6. Socio-ecomomic, institutional and environmental challenge $(n=73)$

\begin{tabular}{ccc}
\hline Socio economic challenge & Respondent & \% \\
\hline Lack of knowledge & 23 & 31.5 \\
Lack of material & 33 & 45.2 \\
Cost maintenance & 17 & 23.3 \\
Total & 73 & 100.0 \\
Environmental challenge & & \\
Poor vegetation & 12 & 16.4 \\
Climate condition & 24 & 32.9 \\
Soil condition & 37 & 50.7 \\
Total & 73 & 100.0 \\
Institutnal challenge & & \\
Poor training on technology & 20 & 27.47 \\
Poor implementation & 19 & 26 \\
Poor monitoring and evaluation & 12 & 16.4 \\
Lack of awareness & 22 & 30.13 \\
Total & 73 & 100.0 \\
\hline
\end{tabular}

Sources: structural interview of wereda demonstration office, (2020)

\section{Conclusions and Recommendation}

Based on the above results soil fertility decline, forest degradation, erosion, deforestation and limited use of conservation measures, poverty, lack of awareness and lack of martial are the major underline cause and soil fertility decline forest degradation are the major form of land degradation in the study area. As it was clearly indicated in the result and discussion part as the respondent indicated the major land rehabilitation practice undertaken by the farmers are some different SWC practices, a forestation and reforestation, crop rotation and intercropping. In the study area lack of awareness poor implementation design, and poor monitoring and evaluation of newly introduced land rehabilitation technology is considered as major institutional gap and affect effective use of technology from community point of view and the environmental challenge are soil condition, poor vegetation cover and climate conditions are the major environmental challenge respectively in the study area are the majority of family members are willing to participate in any natural resources conservation activities. The cooperation among the societies to rehabilitation degraded land areas on their farm plot and community land respondent show that majority of the people in their localities are willing to perform any resource management practices. 


\section{References}

[1] Alemneh Dejene (2003) .Integrated Natural Resource Management to Enhance Food Security, the Case for Community Based Approaches in Ethiopia, Environment and Natural ources Working Paper No. 16, FAO, Rome.

[2] Berry L. (2003). Land Degradation in Ethiopia: Its Extent and Impact Commissioned by the GM with WB Support Benin, S. (2002). Policies Affecting Land Management, Impact Use and Productivity: Land Distribution and Tenure in the Highlands of Amhara region. ILRI paper.

[3] Belayneh A. (2005). Land Degradation Assessment and Evaluation of Current Land Use and Soil Conservation Structures at Upper Chena Catchments, Southern Gondar, Ethiopia. MA Thesis (unpublished); Addis Ababa University, Addis Ababa, Ethiopia.

[4] FAO (Food and Agriculture Organization) (1996). Ethiopian Highlands Reclamation Stud (EHRS). Fi- nal Report.

[5] Kruger.H, Berhanu Fantew, Yohannes Gebre Michael and Kefeni Kejela(2001). Inventory of Indigenous Soil and Water Conservation Measures on Selected Sites in the Ethiopian highlands, University of Bern, Center Development and Environment.

[6] Lament (2010). Ethiopia's Agricultural Sector Policy and Investment Framework (PIF) 2010-2020.

[7] Tesfaye Tanto and Fnuel Laekemariam (2019). Impact of soil and water conservation measures on soil properties and wheat productivity in Southern Ethiopia.

[8] Tilahun A, Takele B and Endrias G (2001). Reversing the degradation of arable land in the Ethiopian highlands. Managing Africa's soils No. 23. International center for research in agro forestry. pp.1-20.

[9] WMO (World Meteorological Organization) (2005). Climate and land degradation. http://www.wmo.int/ web/wcp/agm/agmp. 